\title{
A CONSTITUIÇÃO DO ETHOS DO ORADOR EM EDITORIAIS DO JORNAL DIÁRIO DE NATAL
}

\author{
Ana Cláudia Sousa Neves \\ Grupo de Pesquisa Linguagens e Práticas Sociais - IFRN. Bolsista de Iniciação \\ Científica/IFRN. Aluna da licenciatura em Química /IFRN - Campus Pau dos Ferros. \\ trakinac_02@hotmail.com \\ Claudiane Felix de Moura \\ Grupo de Pesquisa Linguagens e Práticas Sociais - IFRN. Bolsista de Pesquisa \\ (Coordenadora)/IFRN. Professora de Língua Inglesa/IFRN - Campus Pau dos Ferros. \\ claudianemoura@bol.com.br
}

\section{RESUMO}

O nosso trabalho tem o intuito de abordar o estudo sobre a constituição do ethos do orador em editoriais do jornal Diário de Natal. Esse tema foi delimitado para compreender um pouco mais sobre a construção do ethos que se associa à imagem que o orador constrói de si em seu discurso. Este trabalho é referente à pesquisa "Argumentação em textos jornalísticos: um estudo sobre a constituição do ethos do orador", que por ora realizamos no Instituto Federal de Educação Ciência e Tecnologia do Rio Grande do Norte (IFRN) - Campus Pau dos Ferros. O trabalho está fundamentado basicamente nos estudos de Amossy (2008) e Oliveira (2005). As análises tomam por base dois editoriais retirados do jornal Diário de Natal intitulados Cidadania em sua plenitude e Imensa dívida. As análises ainda se encontram em andamento, mas guiamo-nos pela hipótese de que em todo ato de argumentação podemos construir uma imagem do orador. Sendo assim, podemos notar que o ethos é um fator importante para os estudos lingüísticos juntamente com a argumentação, que é de extrema importância para o convencimento e persuasão do auditório, haja vista que a construção dessa imagem do orador é um fator que influencia de forma direta no processo da argumentação e nos seus resultados.

PALAVRAS-CHAVE: ethos, editorial, argumentação.

\section{THE CONSTITUTION OF THE ORATOR'S ETHOS IN EDITORIALS OF THE NEWSPAPER JORNAL DE NATAL}

\begin{abstract}
Our work aims to approach the study of the constitution of the orator's ethos in editorials of the newspaper Jornal de Natal. This theme was delimited in order to understand a little more about the construction of the ethos which is associated with the image the orator builds about himself in his discourse. This work is related to the research "Argumentation in newspaper texts: a study about the constitution of the orator's ethos", that we now realize at Instituto Federal de Educação Ciência e Tecnologia do Rio Grande do Norte (IFRN) - Campus Pau dos Ferros. This work is based on the studies of Amossy (2008) and Oliveira (2005). The analysis was made in two editorials taken from the newspaper Diário de Natal entitled Citizenship in its plenitude and Great debt. The analysis is still in progress, but we lead our work through the hypothesis that in every argumentation act we can build an orator's image. This way, we can notice that the ethos is a very important factor for linguistic studies together
\end{abstract}


with argumentation, that is of extremely importance for the persuasion of the audience, considering that the construction of this orator's image is a factor that influences directly the process of argumentation and its results.

KEY-WORDS: ethos, editorial, argumentation. 


\section{A CONSTITUIÇÃO DO ETHOS DO ORADOR EM EDITORIAIS DO JORNAL DIÁRIO DE NATAL}

\section{INTRODUÇÃO}

O nosso trabalho tem o intuito abordar o estudo sobre a constituição do ethos do orador em editoriais. Esse tema foi delimitado para compreender um pouco mais sobre a construção do ethos que se associa à imagem que o orador constrói de si em seu discurso. Este trabalho é referente à pesquisa "Argumentação em textos jornalísticos: um estudo sobre a constituição do ethos do orador", que por ora realizamos no Instituto Federal de Educação Ciência e Tecnologia do Rio Grande do Norte (IFRN) - Campus Pau dos Ferros. Podemos criar o ethos do orador em qualquer tipo de discurso, desde conversas casuais até discursos importantes. Sendo assim podemos notar que o ethos é um fator importante para os estudos lingüísticos e que juntamente com a argumentação que é de extrema importância para o convencimento e persuasão do auditório haja vista que a construção dessa imagem do orador é um fator que influencia de forma direta no processo da argumentação e nos seus resultados.

\section{FUNDAMENTAÇÃO TEÓRICA}

A argumentação está presente em todos os lugares e discursos, sendo que nós que convivemos em sociedade interagimos constantemente usando recursos persuasivos expondo nosso parecer, defendendo opiniões, ideias e buscando a troca de informações, fazendo uso delas. Segundo Abreu (2001), argumentar é a arte de convencer e persuadir. Convencer é construir algo no campo das idéias. Quando convencemos alguém, esse alguém passa a pensar como nós. Persuadir é construir no terreno das emoções, é sensibilizar o outro para agir. Quando persuadimos alguém, esse alguém realiza algo que desejamos que ele realize.

É importante salientar que a argumentação é imprescindível ao editorial. Para que o jornal manifeste uma opinião que seja aceita pelo público, ele conquista o leitor através da persuasão em relação ao assunto debatido e o editorial tem justamente a finalidade de expor, por meio opinativo, suas idéias, através de sua estrutura argumentativa, para ganhar o público e fazê-lo seguidor de suas idéias.

Segundo Cardoso (s.d), para se conseguir persuadir pelo caráter, o discurso deve ser montado de tal forma a passar a impressão de que o orador é digno de fazê-lo. Um dos segredos da persuasão está no orador passar uma imagem favorável de si mesmo, imagem essa que deve seduzir o auditório e captar a benevolência e a simpatia deste. Essa representação do orador é o próprio ethos, equivalendo ao caráter que o orador atribui a si mesmo pelo modo como exerce sua atividade retórica. Não se trata de fazer afirmações auto-elogiosas sobre a sua própria pessoa no conteúdo do seu discurso, pois declarações essas podem, ao contrário, causar uma impressão desagradável no auditório, mas da aparência que lhe confere a fluência, a entonação calorosa ou severa, escolha das palavras, dos argumentos (fato de escolher ou negligenciar um argumento em específico pode aparecer sintomático de uma qualidade ou de um defeito). O ethos funcionaria como um elemento que reforçaria a plausibilidade da argumentação exposta, o que, não se deve tanto aos aspectos morais do orador, mas sim àquilo que é resultado do próprio discurso; o que é vital, neste tocante, é que a confiança imputada no orador seja um "efeito" do discurso deste. Dois termos que serão bastante utilizados nesta abordagem de ethos e argumentação são eles: orador e auditório. Esses são correlatas, as quais servem para se referir, respectivamente, aos pólos de produção e de recepção dos discursos. PERELMAN e OLBRECHTS - TYTECA chamam a atenção de que "se quiser agir, o orador é obrigado a adaptar-se a seu auditório" (1958, p.37). 


\section{METODOLOGIA}

As análises a serem feitas tomam por base dois editoriais retirados do jornal Diário de Natal, são eles: "Cidadania em sua plenitude" (ANEXO A) e "Imensa dívida" (ANEXO B). Analisaremos a construção do ethos em cada editorial, verificaremos prioritariamente os argumentos usados pelos editorialistas para defender suas teses, e a imagem que o jornal quer expressar ao leitor.

\section{RESULTADOS E DISCUSSÕES}

O editorial "Cidadania e sua plenitude" fala sobre as eleições e a falta de fiscalização dos eleitores para com os eleitos. O editorial impõe a imagem que o eleitor deveria se preocupar após sua ida às urnas, pois muitas vezes ele não faz o seu papel de fiscalizar aquelas pessoas em quem depositaram a sua confiança e o seu voto, deixando de se preocupar com o que será feito no decorrer do mandato daquele que foi eleito. O jornal denota um ethos preocupado com a situação política e procura alertar os eleitores para que zelem pelo seu voto e fiscalizem os seus eleitos, para que os mesmos possam fazer um bom trabalho pelo país.

No segundo parágrafo, o jornal Diário de Natal cita a seguinte afirmação: "Curiosamente, o país que tem a maior eleição informatizada, das mais tranqüilas e universalizadas do mundo". Ao utilizar a definição expressiva, o jornal expõe, como seu ponto de vista, que as eleições estão mais tranqüilas. "É como se depois do comparecimento às urnas, o trabalho dos eleitos fosse entregue a eles de bandeja e o povo mudasse para o outro lado do cenário, para assistir passivo ao desenrolar das próximas cenas". Utilizando o argumento do ridículo, o jornal cria uma situação irônica sobre o voto e mostra a falta de interesse dos eleitos.

No terceiro parágrafo o editorialista propõe que: "é preciso a consciência e, mais do que ela, a prática da cidadania em todas as instâncias". Utilizando a definição expressiva sobre a conscientização e a prática da fiscalização dos eleitos, novamente percebemos um ethos preocupado com a falta de interesse dos eleitores depois das eleições.

Finalmente, no quarto parágrafo o jornal faz menção à seguinte afirmação: "O que ainda se observa no Rio Grande do Norte, a exemplo do restante do país, é uma maioria de eleitores que se comporta como se o ato de votar tivesse fim em si mesmo". Utilizando a técnica do exemplo, o jornal denota ainda que, no Rio Grande do Norte e em todo o país, para a maioria dos eleitores o ato do voto termina depois da ida às urnas.

No editorial "Imensa dívida", cria-se uma imagem das necessidades do Brasil em relação ao analfabetismo e à falta de investimento em relação à deficiência comentada.

No primeiro parágrafo, o jornal cita a seguinte afirmação: "Incapazes de ler o nome do país em que vivem, há no Brasil 14,1 milhões de pessoas maiores de 15 anos que, se soubesse, escreveriam um bilhete em protesto contra a escuridão em que se encontram"._Utilizando a técnica do ridículo, o editorialista faz menção a uma situação irônica sobre o analfabetismo, e o jornal cria esse ethos como um protesto contra os brasileiros que não conseguem nem ler nem escrever. Ainda no primeiro parágrafo é colocado que: "Faltam recursos para oferecer ensino atraente e o cidadão é inibido pela vergonha de não saber ler e pela luta contra a pobreza do dia a dia". Usando a técnica da analogia, inclui a pobreza como um dos fatores que leva as pessoas a não procurarem aprender a ler e a escrever, criando uma imagem de culpa dos analfabetos por não saberem ler em função da pobreza do dia a dia. 
No segundo parágrafo, há a seguinte colocação: “Contudo, no ritmo em que o país vem reduzindo seu vergonhoso estoque de analfabetos, especialistas ouvidos pela reportagem já colocam em dúvida até mesmo o piso compromissado". Utilizando a técnica da definição expressiva, expondo o seu parecer sobre o inverso, ao invés da diminuição estaria acontecendo o crescimento de analfabetos. Cria-se, dessa forma, uma imagem de indignação sobre as metas não cumpridas pelas diversas propostas expostas.

Logo no terceiro parágrafo, o editorialista faz a seguinte colocação como assunto principal: "Como sabemos, a exemplo do que ocorre em vários países do mundo, a educação é um dos suportes fundamentais do processo de desenvolvimento econômico e social". Logo no princípio deste parágrafo o jornal denota o argumento pelo exemplo, através do qual sugere a imitação das ações de um trabalho em vários países do mundo. "O país precisa implantar, com firmeza, amplas políticas educacionais, que atinjam largos segmentos da sociedade brasileira." Aqui, o jornal usa o argumento da definição expressiva impondo o seu ponto de vista em relação às necessidades do país.

Comparando os dois editorais, percebe-se o editorial "Cidadania e sua plenitude" transmite uma imagem preocupada com as eleições e o papel do cidadão em relação ao abandono pelos eleitores de seu papel de fiscalizar o voto depois da ida às urnas. Já o editorial "Imensa dívida" passa um ethos preocupado com o analfabetismo e a falta de investimento para erradicar esse problema. Portanto, ambos defendem e transparecem um ethos preocupado com o país e com a falta de atenção para assuntos que exigem medidas sérias para serem resolvidas, apelando sempre para o auditório.

\section{REFERÊNCIAS}

1. AMOSSY, R. Da noção retórica de ethos à análise do discurso. In: AMOSSY, R. (org.). Imagens de si no discurso: a construção do ethos. São Paulo: Contexto, 2008.

2. OLIVEIRA, M de F. C de. O discurso e a construção do ethos. 2005

3. CARDOSO, M. Editorial: construído ethos e situação enunciativa. s.d

4. Diário de Natal, 27 de Outubro de 2010. Disponível em: <http://www.diariodenatal.com.br/2010/10/27/editorial.php> Acesso 28 de out de 2010

5. Diário de Natal, 04 de Outubro de 2010. Disponível em:< http://www.diariodenatal.com.br/2010/10/04/editorial.php> Acesso 28/10/2010 
ANEXO A:

\section{CIDADANIA EM SUA PLENITUDE}

Candidatos do Brasil inteiro foram ungidos pelas urnas. São os novos deputados estaduais, federais, senadores, governadores país afora, em uma das eleições mais tranqüilas dos últimos tempos. Agora, contabilizados os votos, chegou a hora de se exercer o outro lado da cidadania, bem menos conhecido dos brasileiros: o de acompanhar e fiscalizar os mandatos.

Curiosamente, o país que tem a maior eleição informatizada, das mais tranqüilas e universalizadas do mundo, e um conjunto de centenas de regras regulando o pleito, ainda tem um povo que pouco participa da atividade política após passado o voto. É como se depois do comparecimento às urnas, o trabalho dos eleitos fosse entregue a eles de bandeja e o povo mudasse para o outro lado do cenário, para assistir passivo ao desenrolar das próximas cenas.

É preciso a consciência e, mais do que ela, a prática da cidadania em todas as suas instâncias. Cada eleitor, agora, recebe a responsabilidade de acompanhar o político em quem depositou sua confiança. O problema da saúde tem a ver com ele? $\mathrm{O}$ da segurança? $\mathrm{O}$ da educação? Não há relação distinta entre causa e efeito. O político está lá para representar seu eleitor e brigar por ele, e para retribuir coletivamente cada voto que individualmente recebeu nas urnas.

O que ainda se observa no Rio Grande do Norte, a exemplo do restante do país, é uma maioria de eleitores que se comporta como se o ato de votar tivesse fim em si mesmo. Começasse com a escolha, passasse pelo compromisso e terminasse no voto. Mas o voto é o início da relação entre o eleitor e o eleito. A partir dele deve se estabelecer um novo ponto de partida, no qual o candidato tem a obrigação de prestar contas e seguir os rumos indicados por quem lhe escolheu. E cada um dos cidadãos que contribuiu, ontem, para a festa da democracia, deve assumir sua condição de partícipe ativo dela. Até as próximas eleições. 


\section{ANEXO B}

\section{IMENSA DÍVIDA}

Incapazes de ler o nome do país em que vivem, há no Brasil 14,1 milhões de pessoas maiores de 15 anos que, se soubesse, escreveriam um bilhete em protesto contra a escuridão em que se encontram. Sobram-lhes razões. Em pleno século 21, essa é uma chaga que coloca em dúvida os propalados avanços do país rumo ao mundo desenvolvido e a pretensão de ocupar posição de destaque entre as oito maiores economias do planeta. Os dados são da Pesquisa Nacional por Amostra de Domicílios (PNAD), concluída em 2009, com base de dados levantada em 2007. Há poucas indicações que esse que quadro tenha melhorado significativamente. Aliás, se pudessem, os autores do bilhete às autoridades acrescentariam pedido de mais apoio aos programas e aos abnegados professores do ensino para jovens adultos. São enormes as dificuldades enfrentadas pelos que se dedicam a levar as luzes do alfabeto a adultos e mesmo a jovens. Faltam recursos para oferecer ensino atraente e o cidadão é inibido pela vergonha de não saber ler e pela luta contra a pobreza do dia a dia. Nem todos têm a sorte e o talento do palhaço Tiririca que provocou, ao receber um milhão e trezentos mil votos, polêmica entre juristas e intelectuais.

Essas pessoas, sem qualquer preparo escolar, não fazem ideia do que são as Metas do Milênio, definidas em 2000, pela Conferência Mundial de Educação, em Dacar, sob o patrocínio da Organização das Nações Unidas para a Educação, a Ciência e a Cultura (Unesco). O Brasil comprometeu-se a chegar em 2015 com taxa de analfabetismo de no máximo $6,7 \%$ da população. A meta estava longe de ser ousada e, a bem da verdade, deveria ter sido bem mais perto de zero. Contudo, no ritmo em que o país vem reduzindo seu vergonhoso estoque de analfabetos, especialistas ouvidos pela reportagem já colocam em dúvida até mesmo o piso compromissado.

Como sabemos, a exemplo do que ocorre em vários países do mundo, a educação é um dos suportes fundamentais do processo de desenvolvimento econômico e social. Somente ela consegue preparar o cidadão para o exercício pleno dos seus direitos, dando-lhe oportunidade para participar dos resultados desse desenvolvimento. O país precisa implantar, com firmeza, amplas políticas educacionais, que atinjam largos segmentos da sociedade brasileira.

Seja em razão do referido compromisso, de âmbito internacional, com as Metas do Milênio, seja com outro que deveria ser ainda muito mais importante, com a consciência nacional e o respeito a essa multidão de analfabetos, não é aceitável andar tão devagar, quase parando, com tamanha prioridade. Seja qual for o próximo governo, um programa que mobilize recursos e pessoas no combate ao analfabetismo, de maneira a tornar modesto o compromisso assumido com a Unesco, terá de ser obrigação. É hora de o país pagar essa dívida desonrosa em relação a 14 milhões de brasileiros. 